\title{
PERSISTENT PATENCY OF THE DUCTUS ARTERIOSUS BOTALLI IN THE DOG*
}

\author{
CLYDE BROOKS \\ PITISBURGH, PA.
}

This case is reported because it includes not only the ordinary clinical observations, but also direct manometric blood-pressure and intratracheal respiratory pressure tracings, together with autopsy findings with histological report, all on a dog which had a widely patent ductus arteriosus Botalli with aneurysm of the duct itself and the beginning systemic and pulmonary aortæ. A further favorable condition was that death in this case was caused by rapid suffocation. By this means the physiological and pathological conditions or changes caused by the persistent patency of the ductus were all preserved unobscured by any other overshadowing diseased condition as is usual at autopsy.

From a study of the case from these different points of view, it seems that the clinical symptoms and abnormalities in blood-pressure and respiration, and the changes found in the various organs, which were associated with the persistent ductus, are all related, and apparently constitute a condition as a whole which leads to a tolerably satisfactory conception of the nature and cause of the changes present.

The case reported here is that of a dog which was used for a demonstration in the Pharmacological Laboratory of the University of Pittsburgh. Following are some of the notes from the clinical description based on the examination preliminary to anesthetizing the animal:

\section{NOTES ON CLINICAL EXAMINATION}

March 15, 1910, 2:30 p. m.: Adult well-nourished male dog with yellow hair. Weight 14,000 gm. Behavior normal, rather quiet, not excited. Respiration 10 in ten seconds. (Owing to his looking about and inquisitively sniffing the air, some difficulty was experienced in making the observation.)

At 2:48 p. m.: Pulse from the femoral artery 21 in ten seconds, somewhat irregular, showing a periodic symmetrical arhythmia, which seems to bear a close relationship to the respiratory movements. Inspection showed a greatly exaggerated cardiac impulse, both as to force of impulse and as to area of surface involved in the movements of the heart beat, and also brought out clearly the periodic arhythmia which was observed in counting the pulse. In addition there was a powerful thrill. This thrill continued and swelled out strongly during systole and was less powerful, though still very well marked, during diastole. Tentative diagnosis made at this time: Aneurysm with aortic regurgitation.

*From the Laboratories of Physiology and Pharmacology of the University of Pittsburgh. 


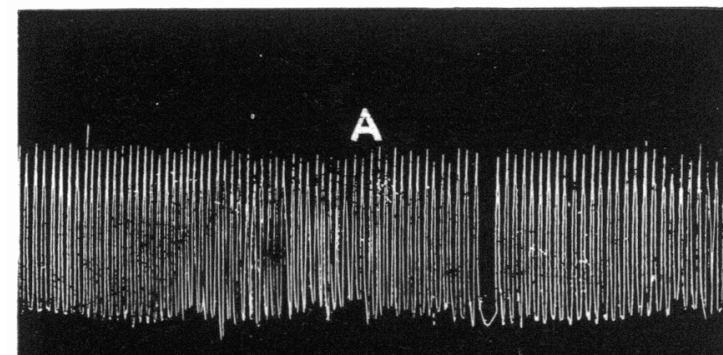

B

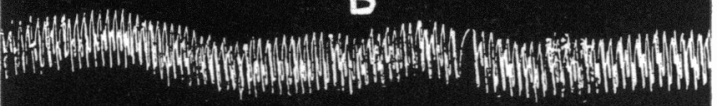

C

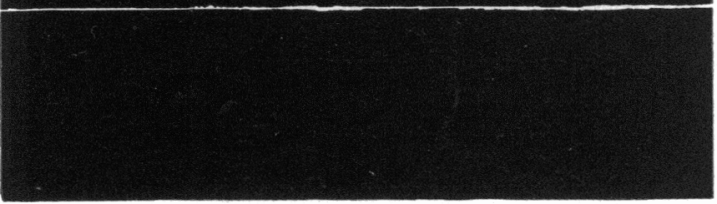

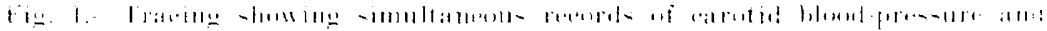

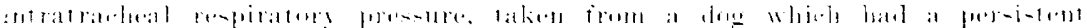

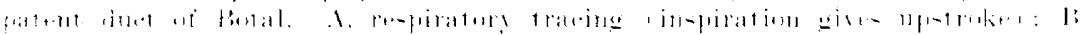

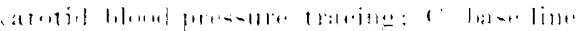


At 2:50 p. m.: Pulse 21 in ten seconds. Respiration 5 in ten seconds. Pupils measured in the bright light $2.5 \mathrm{~mm}$. in diameter.

Following are some of the notes made during the demonstiation which show the results of anesthesia and blood-pressure and respiration observations. They are sufficient to show the character of the pulse and respiration.

\section{NOTES ON BLOOD-PRESSLRE AND RESPIRATION}

2:5l p. m.: Began the administration of ether. Animal struggled.

2:51:45 p. m.: Animal relaxed but slightly, and winked its eyes frequently.

2:52:15 p. m.: Pupils dilated. Dog still winking.

2:52:30 p. m.: Pulse 33 in ten seconds. Respiration 9 in ten seconds.

2:53 p. m.: Pupils dilated. No reflex on touching the conjunctiva. Intraorbital pressure considerably increased.

2:54 p. m.: Pulse 39 in ten seconds. Respiration 12 in ten seconds.

2:55 p. m.: Animal not well relaxed. Anesthetic increased.

2:56 p. m.: Animal sufficiently well relaxeil. Operation begun. Tracheal cannula inserted, connected with the ether bottle and with a short side connection to a tambour which gave upstrokes on inspiration. Three-way cannula inserted jnto right common carotid artery and connected with a mereury manometer by a short rubber tube. The ether was crowded to the maximum by shutting off entirely the air-hole in the tracheal cannula and by shaking the ether bottle.

3:00 p. m.: Pulse 36 in ten seconds. Respiration 15 in ten seconds. Began blood-pressure and respiratory tracings.

3:01:30 p. m.: Pulse 36 in ten seconds. Respiration 12 in ten seconds.

3:02 p. m.: Pulse 32 in ten seconds. Respiration 12 in ten seconds.

3:02:30 p. In.: Pulse 29 in ten seconds. Respiration 15 in ten seconds.

Remark.-Throughout these counts the pulse alternated in character. First, one beat was very strong and trip-hammer in character, while the next one was very weak. Occasionally there were complete notches or omissions.

These observations are sufficient to give the main characters of the blood-pressure changes and respiratory movements and to show their relation to each other. Measurements of the blood-pressure tracing taken by an ordinary mercury manometer (without maximal or minimal valves) show (Fig. 1) a mean pressure of about $164 \mathrm{~mm}$. The minimal shown on the tracing is $156 \mathrm{~mm}$. and the maximal is about $172 \mathrm{~mm}$. The rate of respiratory movement is generally about one-half that of the pulserate. During inspiration the blood-pressure falls; and during expiration it rises.

Then follow observations of the action of magnesium sulphate on the animal and finally death, which was caused by clamping the trachea.

When the thorax was opened, aneurysmal dilatation of the beginning systemic and pulmonary aortæ was observed; but patency of the duct of Botal was not yet suspected.

Following is a brief summary of the chief findings of the autopsy which was held about an hour after the death of the animal:

\section{NOTES ON AUTOPSY}

March 15, 1910, 5:30 p. m.: The body is that of a well-nuurished male dog with short yellow hair. Iength of body from tip of nose to root of tail, $55 \mathrm{~cm}$. Weight about 14 kilos. Body slightly warm and not in rigor mortis except 
wightly in the jawn and shoulders. Pupils moderately diated. Selera clear white. Large recent open womel extending lengthwise from the throrod cartilage to the diaphragm and opening the thorax all the way down in the mid-line. superficial lymph-glamels not palpable. So otlor external abnormalities.

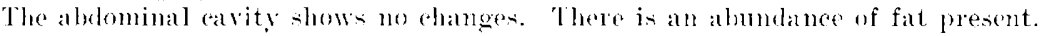
The lidheys are rathor small and firm: their cut surface is pale. and shows the

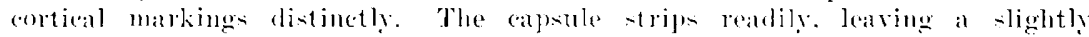

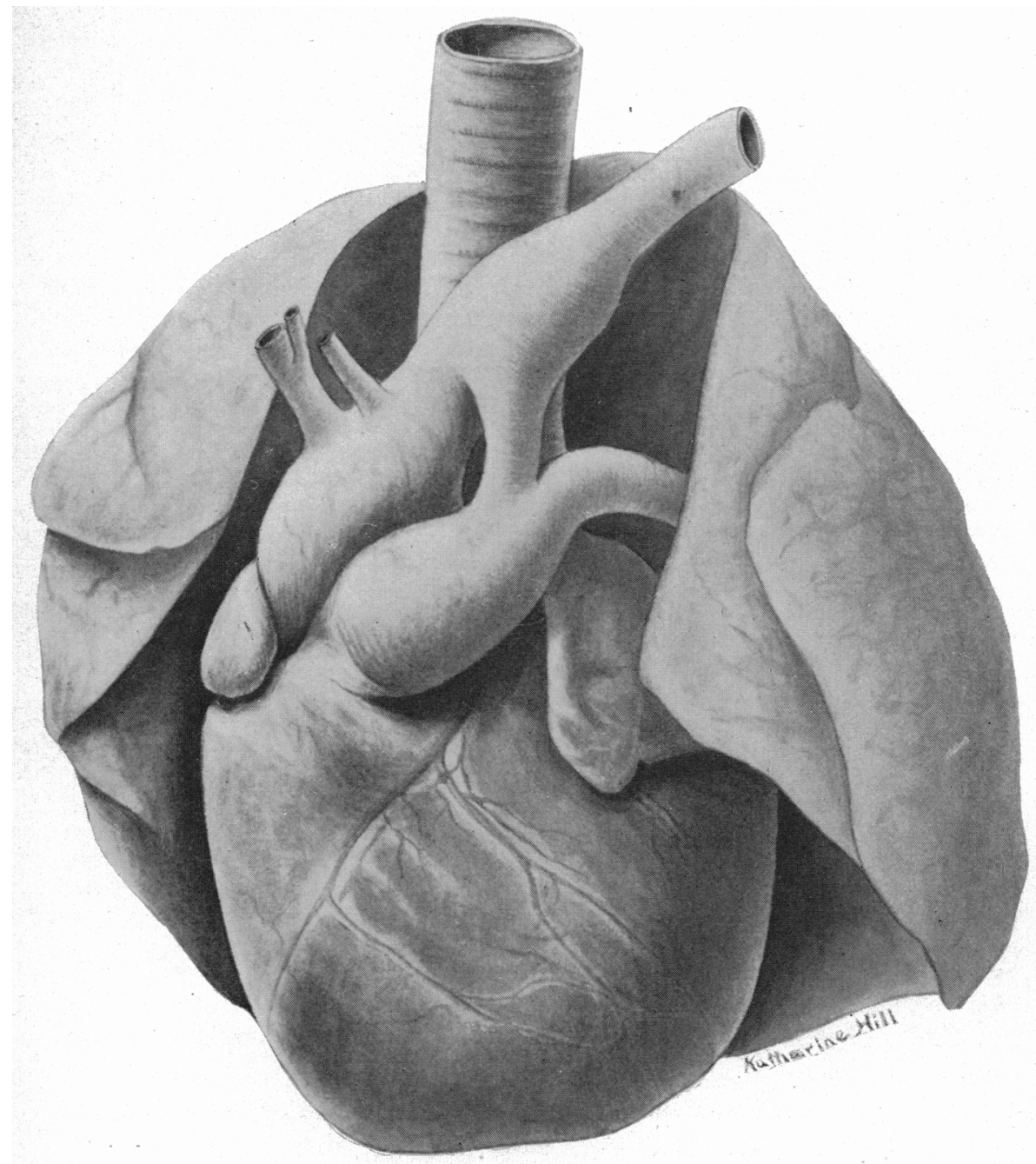

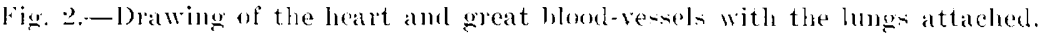
- hawing the persistent ductus arteriosus botalli.

gramular surface. The liver is dark in color and foels rather firm; the cut surface shows nothing abnormal. The gall-bladder is distended with pale green lite. Fxamination of other ableminal visera shows no abnormalities.

Both lobes of the thyod are sma!l and poor in colloid. The parathyroids are normal. The lymph-glands in general are not enharged. The bronehial lymph- 
glands are black but not swollen. The heart and its accompanying large vessels and the lungs are removed en masse. The lungs contain considerable black pigment. They are slightly discolored, and show small areas of emphysema (due doubtless to positive artificial respiration). They feel slightly tough and leathery, and they do not collapse quite so readily as normally. There are no areas of consolidation or cavities. The cut surface shows that the branches of the pulmonary arteries stand open. There are no other apparent abnormalities.

The heart is very large, broad and euriously blunt-looking (Fig. 2), resembling in shape a turtle's heart. The apex is made up entirely of left ventricle. The walls of the left ventricle are greatly thickened, measuring $20 \mathrm{~mm}$, near the base. A less thick area is palpated near the apex. The walls of the right ventricle, which occupies only the upper and right side of the heart, are also much thick: ened. They measure at points near the base 5 to $6 \mathrm{~mm}$. Both auricles are also thickened. The interventricular septum measures from 10 to $12 \mathrm{~mm}$. The cavity of the left ventricle is greatly enlarged. The other cavities of the heart are about normal in size. The foramen ovale is closed. The auriculoventricular openings are normal in size. Both aortic openings of the heart are also normal in size. All the aortic and mitral and tricuspid valves are normal, except that they appear stronger and heavier than normal. This is especially true of the mitral leaflets. The coronary arteries are thickened but show no patches. The systemic and pulmonary aortæ are laid open by a cut beginning from a point on the ventricles about $3 \mathrm{~cm}$. below the mouth of the coronary artery and extending upward to a point far enough to expose the mouths of thirteen intercostal arteries inside the aorta. The circumference of the aortic orifice when laid open measures $4.5 \mathrm{~cm}$; that of the pulmonary, $4.2 \mathrm{~cm}$. The beginning aorta just above the aortic orifice forms a large bulbous dilatation. The intima in this region is smooth, but the vessel wall is of a diffuse slightly yellowish color. At the widest part the vessel laid open measures $5.8 \mathrm{~cm}$. There is a similar bulbous dilatation at the beginning pulmonary aorta, with similar yellowish coloration of the walls, but with glistening intima. This dilatation is not so large as that of the systemic aorta. It measures, laid open, $5.4 \mathrm{~cm}$. in the widest part. At a point just opposite the region where the arterial ligament normally comes off from the systemic aorta, there is a second widening of its lumen into an oval bulbous dilatation. This bulb is smaller than either of the other two. Its wall measures $5 \mathrm{~cm}$. in width when laid open. There is no narrowing of the aorta beyond the region of the ductus. The intima is smooth and glistening. The vessel wall has a slightly yellowish color. Coming off from this dilatation and connecting it with the pulmonary aorta is the widely patent duct of Botal (Fig. 2). This duct is itself widely dilated at the aortic end and narrows gradually till just at the pulmonary opening where it narrows abruptly. The duct is therefore funnel-shaped with the wide end opening into the aorta, and the narrow end opening into the pulmonary aorta. Its aortic opening is about $14 \mathrm{~mm}$. in diameter. (It cannot accurately be determined, for it merges at the distal side into the wall of the aorta without any line of demarcation.) Laid open it measures $43 \mathrm{~mm}$. The pulmonary opening forms a smooth elevated ring apparently composed of thickened intima. This ring is surrounded by an elevation which appears to form a nozzle-like ostium. The pulmonary opening, which is almost a perfect circle, is 4.5 to $5 \mathrm{~mm}$. in diameter. The length of the duct itself is about $20 \mathrm{~mm}$. The whole effect is that the duct itself forms a rather bulbous, pouch-like, funnelshaped tube which originates from the aorta with a very wide mouth, almost as wide as the normal aorta itself, and opens into the pulmonary aorta with a much smaller mouth. The effect of the opening at the aorta is to leave at the proximal (nearest the heart) margin a sharp edge in the blood-stream. The pulmonary opening is almost half the diameter of the normal pulmonary aorta itself. This patent duct of Botal is connected at an angle of about 40 degrees with the systemic and pulmonary aortæ.

After the autopsy and before placing the specimen in preserving fluid, the continuity of the heart and great vessels and ductus arteriosus was restored by 
suturing with fine silk. I wish at this point to thank Prof. C. C. Guthrie for the accomplishment of this task. I then made the drawing which is intended to give an impression of the appearance of the heart and great vessels with lungs attached, all parts being made true to scale as measured at this time. The drawing which is published here (Fig. 2) is a copy made later from this measured drawing, together with the preserved specimen.

\section{HISTOLOGICAL REPORT}

Tissues were fixed in Zenker's fluid, embedded in celloidin, and stained with hematoxylin and eosin, and also with orcin. The histological findings are remarkable principally on account of the absence of many marked abnormalities which might have been suspected.

The heart showed nothing abnormal. The branches of the pulmonary were large and heavy walled, but showed no inequalities in the thickness of the different layers in different ares of the circumference, nor any patches nor fatty changes. The elastic tissue was normal in amount and appearance. In many areas the lungs showed thick-walled alveoli. The blood vessels were prominent and the capillaries were over-filled with blood. The capillaries in places bulged out into the lumen of the alveoli, forming bud-like projections. The lungs contained a large amount of pigment as is usual in dogs in Pittsburgh. Elastic tissue was present in fully the normal amount. There were no Herzfehlerzellen or other evidence of chronic passive congestion of the lungs. Scattered throughout the section were many areas showing enlarged nodular masses of plain muscle surrounding the bronchioles. There was an exudation in the bronchi, and some areas of emphysema and atelectasis.

The spleen showed a large proportion of trabecular tissue with the Malpighian hodies irregular in size and distribution. The blood-vessels of the spleen were somewhat sclerotic. There were also cells bearing golden-brown pigment. The capsule was wrinkled. The portal branches in the liver were distended. The blood capillaries were well filled, but not to the point of congestion. The livercells were normal except for very slight fatty changes.

The kidneys were normal except for a slight increase in interstitial connective tissue.

The lungs were in very good condition except the exudate into the bronchi and the patches of emphysema, which were no doubt due to the long-continued positive artificial respiration; and also except some thickening of the branches of the pulmonary arteries, and areas of bud-like dilatation of the capillaries, together with many enlarged nodules of plain muscle surrounding the terminal bronchioles and with some thickening of the alveolar walls.

There was chronic passive congestion of the spleen which had previously been greater than it was at the time of autopsy.

\section{DISCUSSION OF LITERATURE}

Previous to the recent complete review of the literature and discussion of the present status of our knowledge of the whole subject by $\mathbf{H}$. Gideon Wells, ${ }^{1}$ there was no adequate treatment of this matter in English; but his article renders unnecessary any extensive review or discussion of literature at this time.

Also there is a splendid article by Goodman ${ }^{2}$ dealing especially with the symptoms and physical signs, and containing a bibliography.

I. Wells, H. Gideon: Persistent Patency of the Ductus Arteriosus Botalli, Am. Jour. Med. Se., 1908 (136), 381.

2. Goodman, Edward H.: Report of a Case of Patent Ductus Arteriosus Botalli, with a Study of the Cases Heretofore Published, Univ. of Penn. Med. Bull., Phila., 1910, xxiii, 509. 
The occurrence of simple primary patency of the ductus arteriosus Botalli in man is very rare, especially if simple primary patency is understood to include only those cases in which the ductus is open for the transmission of blood without any other overshadowing congenital abnormality, such as stenosis of the pulmonary aorta. Wells reports in the entire literature only forty-one cases, in only twenty of which the patients reached adult life. I have found in the literature at my command, one instance of the condition in the dog. ${ }^{4}$ In aquatic mammals the ductus arteriosus normally remains patent for some time after birth, but an open canal in the adult is regarded as pathologic. For example, persistent patency has been observed in the seal. ${ }^{3}$

As Wells points out with reference to man, so is it with laboratory animals, that if careful systematic search were made at autopsy, more instances would undoubtedly be found.

It is probable that in simple primary patency, such a widely patent ductus arteriosus as the one under observation occurs only extremely rarely.

Lienaux ${ }^{4}$ observed a case of persistence of the duct of Botal in a little $\operatorname{dog} 5$ or 6 months of age, brought to him for treatment because it was weak and refused food. The little dog showed a frequent cough with no expectoration, rapid respiration with audible rough sound. There was an increased dulness over the region of the heart. Palpation gave a frémitus cataire, or a thrill resembling the purring of a cat, which was marked both on the right and the left sides. There was a murmur which was of maximal intensity over the anterior part of the heart. The femoral pulse was strong. The jugular pulse was marked, and coincided with the ventricular systole. Temperature $40.1 \mathrm{C}$. The dog died two days later.

The autopsy showed the left ventricle much enlarged and thickened. The pulmonary orifice was insufficient to the water test. The total volume of the heart was much increased. The duct of Botal was patent and was about the size of the pulmonary aorta, and the walls of the patent duct were thicker and more rigid than those of the pulmonary aorta. 'The beginning systemic aorta was enlarged as far up as the place where the duct of Botal branched off. This aneurysmal part had thin rigid walls. The trachea was compressed by the aneurysm, which accounts for the rough breathing.

Dr. Kate Campbell Mead $\mathrm{M}^{5}$ has reported a case of persistent patency of the duct of Botal in an adult woman. Although the patient had been

3. Jammes and Mandoul: Sur la persistance du canal artériel chez le phoque, Bull. de la Soc. d'hist. nat. de Toulouse, 1905, xxxviii, 3.

4. Liénaux, E.: Un cas de persistance du canal artériel chez le chien, Ann. de méd. vét., 1898, xlvii, 416.

5. Mead, Kate Campbell: Persistent Patency of the Ductus Arteriosus, Jour. Am. Med. Assn., 1910, 1v, 2205. 
troubled with heart symptoms since childhood, she reached adult life and married and went through pregnancy in very fair condition.

Thayer's examination of the patient showed a long machinery murmur over the right ventricle with systolic accentuation, and with accentuation of the second pulmonic. The loudness of the murmur high up suggested to him persistent patency of the duct of Botal. Later the patient showed more aggravated circulatory symptoms with laryngeal cough, edema, meteorism, and scanty urine - leading to coma, and finally very suddenly to death.

Autopsy showed the heart ruptured in three places in the right ventricle, with sclerosis of the coronaries and fatty degeneration of the myocardium. The heart was greatly enlarged, especially in the right ventricle. The heart weighed $395 \mathrm{gm}$. (Normal about $250 \mathrm{gm}$.) All cavities of the heart were enlarged and the walls thickened. The walls of the right ventricle especially were thickened, being almost as thick as those of the left ventricle which were also thicker than normal. The duct of Botal was patent. It was funnel shaped with the large end $1 \mathrm{~cm}$. in width opening into the systemic aorta; and the small end about $4 \mathrm{~mm}$. in diameter opening into the pulmonary aorta, and forming a ring-like ostium of the thickened intima of the pulmonary aorta.

In this case it seems that the persistent patency of the duct of Botal brought on a higher pressure in the pulmonary artery, which eventually led to hypertrophy of the right ventricle with sclerosis of the coronaries of that part of the heart. This condition finally led to fatty degeneration which resulted in weakening of the myocardium and rupture of the heart, which was the immediate cause of death of the patient.

\section{DISCUSSION OF THE PRESENT CASE}

Although there was a profound alteration in the circulatory apparatus in the dog concerned in this report, yet there was no change in the health or general well-being. The dog was in fine health and vigor, and well nourished. There was no blueness of the mucous membranes. There was a heightened blood-pressure with arhythmia of the cardiac beat. Another noticeable change of the circulation was the relation of respiratory movements to blood-pressure change. ${ }^{6}$

6. It is to be remembered that normally in the dog the blood-pressure rises during inspiration and falls during expiration, except the change is slightly later than the change in respiratory movement; that is, the blood-pressure continues to rise for a short time after inspiration has ceased, and it continues to fall for a short time after expiration has ceased. It is known that this relationship between blood-pressure and respiratory movements is not the same in all species of animals nor even in the same species under all conditions, for it is a very complex relationship which is dependent on several factors which vary with the rapidity, depth of respiratory movements, size of animal, and with the preponderance of costal or abdominal respiration. Lewis, Thomas: Further Advances in Physiology, N. Y., 1909, p. 144. 
In this dog the usual condition was reversed. Inspiration was synchronous with a fall while expiration was synchronous with a rise in blood-pressure. The explanation of this is probably that during inspiration while the lungs expanded, the blood from the aorta poured over into them. This drain on the aorta caused a fall in blood-pressure. Then during expiration the volume of the blood-vessels of the lungs was decreased so that the blood was squeezed out of them. This would leave the pulmonary circuit filled so that less blood could escape across from the aorta through the ductus arteriosus into the pulmonary aorta. Because the drain on the aorta was diminished, the blood-pressure would naturally rise in the systemic circuit. Also it is probable that during inspiration as the lungs were expanding less blood was thrown out of them into the left auricle. This would lessen the amount thrown out into the aorta; and during expiration the compression of the lungs would discharge a larger volume of blood into the left auricle which would be immediately cast out into the aorta and would raise the blood-pressure. It acted, according to this conception, as the establishment of a short circuit in the aorta during inspiration and with an interruption of the short circuit during expiration.

The abrupt changes of pressure on the heart coupled with the abrupt changes in the volume of blood coming to the heart are probably associated with the arhythmia of pulse. The sudden fall in pressure in the aorta at the same time with a sudden decrease in the amount of blood coming into the heart from the lungs would be sufficient to account for the omission of beats which was noticed above.

The mixing of artificial and venous blood here must have been very considerable, but was not such as to cause marked blueness of the mucosa. Of course blueness of the skin is not so easily recognized in the dog as in man. But blueness would not be expected in this case, because the mixing, in all probability, consisted only in adding aortic arterial blood to venous blood of the pulmonary artery, and not vice versa; for the minimum aortic pressure recorded in our tracings never closely approached that of normal pulmonary arterial pressure. Direct measurements of the pulmonary arterial blood-pressure were not made in this case; but judging by the records obtained from the carotid which may be considered as giving an index of the systemic aortic pressure, and also by the comparative size of the two ventricles, and since the ventricles appeared to beat synchronously, there is no evidence that the right intraventricular pressure ever overtopped that of the left.

The high blood-pressure of this dog is not necessarily a matter for great wonderment, for it is not uncommon to find in lusty, vigorous dogs under an anesthetic a blood-pressure considerably above the average; furthermore, it is well known that the vascular mechanism is endowed 
with great powers of compensation; and yet the pressure recorded is somewhat higher than the average observed under such conditions of anesthesia. However, high blood-pressure is often associated with persistent patency of the duct of Botal, especially where compensation has occurred.

The principal feature of pathological interest in this case is the patent duct of Botal; and scarcely less important are the changes in the organs found associated with this persistent patency. First of these may be mentioned the bulbous dilatation of the beginning aortæ and the duct itself. These dilatations may have been caused by the impact of the rebound of the column of blood brought about by the sharp changes in blood-pressure. The stretching may also have been favored by the heightening of the general blood-pressure. As to the presence of sclerosis in the vessels it may be said that there are no very profound changes. The arteries appear slightly thickened and stand open when cut, and even show slightly yellowish color in the aneurysmal parts; but there is no atheroma nor roughness of the intimal surfaces. Microscopically they show some thickening of the walls, but no irregularities in thickness in the different parts of the circumference.

The curiously blunted turtle-heart form of this heart was apparently due to compensatory changes. The heart as a whole was considerably larger and heavier than the normal. This hypertrophy was enormous in the left ventricle. The left ventricle occupied the whole of the apex and extended far up on the right side of the heart. The right ventricle also was hypertrophied. The walls of both ventricles were thickened; but the cavities were about normal in size. This peculiar turtle-heart form was apparently due to the compensatory hypertrophy in response to the increased work thrown on the left ventricle, for in addition to its own natural work, it had to pump a large amount of blood through the Iungs. This in turn tended to heighten the pressure in the pulmonary artery which would offer increased resistance to the emptying of the rigbt ventricle, and in that way would induce hypertrophy of that ventricle. All the blood which was short-circuited from the aorta to the pulmonary artery would come back to the left side of the heart and have to pass again through the left auricle. This additional work is sufficient to account for the bypertrophy of this part of the heart. The increased resistance to the emptying of the right ventricle offered by the high pressure in the pulmonary artery could well be the cause of more or less damming back of blood into the right auricle such as might cause compensatory hypertrophy of this part of the heart. Owing to this, all four chambers of the heart were put to additional work, which resulted in compensatory hypertrophy, which was most marked in the left ventricle where the additional work was heaviest. 
The whole pathological condition of this animal is that of a widely patent duct of Botal which acted as a short circuit in the aortic circulation, but which was so well compensated that there resulted no serious impairment of the general health or comfort of the animal. This agrees with the findings of others on man that the prognosis in persistent patency of the duct of Botal is good. Therefore an effort should always be made to differentiate between aneurysm and patent duct of Botal on account of the difference in prognosis. From our experience with this animal it would seem that when necessary to administer an anesthetic to a patient with compensated patent duct, there need be no extraordinary precautions, for this dog showed even more than usual resistance to the effects of ether. 